LM

27,9

600

Received 29 May 2006

Revised 23 June 2006

Accepted 28 June 2006

\section{Indexing change in LIS work: implications for recruiting managers}

\author{
John Cullen and Allison Kavanagh \\ Dublin Institute of Technology, Dublin, Ireland
}

\begin{abstract}
Purpose - The purpose of this paper is to report on three periods of library and information service (LIS) recruitment data collected over a six-year timeframe with the aim of developing a tool for indexing change in the recruitment and labour market for workers in the field.

Design/methodology/approach - The recruitment data were collected in an Irish context over three distinct 12-month timeframes (1999, 2001-2002 and 2005). The two earlier annual sets of data have already been reported and discussed, and the most recent set (2005) is presented here. The data over the three timeframes are compared here, and a practical approach for collecting these data in an ongoing fashion is suggested.

Findings - The article finds that although LIS positions have become less available in 2005 than in previous periods, that remuneration has increased at a rate of 16 per cent.

Originality/value - The value of this approach and the data unearthed are discussed in the context of their value to senior managers and individuals with responsibility for recruitment and strategic human resource management in library and information service context.
\end{abstract}

Keywords Information management, Labour market, Library management, Indexing, Recruitment, Ireland, Human resource management

Paper type Research paper

\section{Introduction}

In developed economies employment stability has become increasingly fragile, and treatments of the impact that this has on professional employees and managers have been widely discussed in the sociological and popular literature (for a recent account of the impact of the transitional nature of professional employment in the American context see Ehrenreich (2006). There have been a number of societal and economic changes on a global scale, which have driven the need for a constant reassessment of the employment needs of organisations in all sectors and for labour market restructuring. These forces have fundamentally impacted on the nature of the employing manager. Cooper (1998, p. 313), for example, writes:

The psychological contract between employer and employee in terms of "reasonably permanent employment or work well done" is truly being eroded, as more and more employees no longer regard their employment as secure and many more are engaged in part-time working.

Cooper points out that although this has been the source of some anxiety for many employees, there are positives that also arise from this, such as a greater sense of control over their own working lives. A strong stress has emerged on the need for organisations to be aware that labour market flexibility can impact negatively on them
Library Management Vol. 27 No. 9, 2006 pp. $600-605$

(C) Emerald Group Publishing Limited 0143-5124

DOI $10.1108 / 01435120610715509$ 
in relation to the pressures that exist with regard to the recruitment and retention of star performers (Michaels et al., 2001).

Ireland has undergone significant economic change over the last decade. The "boom" of the late 1990s led to the emergence of the "Celtic Tiger" economy which has had multiple societal and economic effects. During the height of the economic upturn, the employment market was buoyant, as might be expected, but following the initial negative downturn the recruitment market is currently strong.

The authors' curiosity about how the series of social and economic transformations happening in their local national context were affecting the recruitment market for library and information professionals led them to investigate exactly how these changes were impacting on the ground. It has been established amongst LIS labour market researchers that job postings and employment notices provide ample opportunities for researching the requirements of recruitment markets and for creating significant understandings of emerging opportunities and how LIS professionals might address these (Moore, 1987, 1988; Cote, 1989; Willard and Mychalyn, 1998). An initial attempt to provide an annual "snapshot" of the Irish recruitment market was conducted by sourcing advertisements in the two most extensive weekly newspaper appointments sections and providing a picture of the skills, experience and qualifications being sought (Cullen, 2000). Data on the level of appointments available, sectors where positions were advertised, seasonal variations, salary ranges and locations for appointments were also unearthed. This research acknowledged that the sources from which the data obtained was somewhat limited and that a larger review was required to test their validity. The opportunity to do this was provided by way of funding granted by the Library and Information Research Group/Elsevier research award, which made funding available to employ a news monitoring agency to capture all library and information service appointment notices over the 12 months from April 2001 to March 2002. Additional supplementary information was solicited when indicated (Cullen, 2002). The large level of qualitative and quantitative data made it possible to analyse particular aspects of library recruitment such as the availability of LIS positions in not-for-profit organisations (Cullen, 2004b) and the need to develop management capabilities and competencies amongst LIS professionals in management positions (Cullen, 2004a). It emerged that the sources used to collect data for the first study could be considered to represent a substantial amount of recruitment opportunities when compared to all other sources sourced nationally. Of the 301 advertisements, 48 per cent appeared in the Irish Independent and 58 per cent in the Irish Times - 24.6 per cent appeared in both newspapers. When these incidences of cross advertising are taken into account, analysis shows that 81 per cent of all advertisements sourced appeared in the Irish Times or Irish Independent.

These two studies provided interesting snap shots of recruitment advertising over two distinct 12-month timeframes. By generating a third set of advertisements, based solely on recruitment data from the Irish Times and Irish Independent we are provided with an opportunity for developing a representative time series that could provide the grounds for an ongoing recruitment index of LIS recruitment opportunities that might provide managers with insight into occupational change in their specific locale. Furthermore, if it is possible to construct a representative annual picture of the Irish LIS labour market by sourcing advertisements from two newspapers sections per week, the development of such an index might be practically actionable.

\section{Indexing change in LIS work}

601 
$\mathrm{LM}$

27,9

602

\section{Methodology}

The means by which data was sourced, collected, organised and quantified has been previously mentioned. The appointments sections of the Irish Times and Irish Independent newspapers were scanned for all LIS job postings. These postings were cut, collected and numbered. Data relevant to a number of headings were entered into a Microsoft Access Database and analysed. Data collection for the 2001/2002 project was more extensive, and for the purposes of producing comparable sets of data, only advertisements sourced in the aforementioned publications are referred to here. As in 1999, the most recent set of data (2005) is based solely on employment advertising in the publications mentioned. As the initial project focused on jobs which exist in the "traditional" LIS sector, jobs which were classified in the 2001/2002 project as originating from the "emerging information" sector were not included. This meant eliminating a number of positions that could be held by LIS graduates, but were not identified as specifically being a library positions (e.g. Press and Information Officer, Database Manager, Freedom of Information Officer, etc.).

\section{Overall results}

In 1999, 123 LIS jobs were captured in the sources mentioned. During the 2001/2002 timeframe this grew to 151, and in 2005 this dropped to the lowest level in the series: 102. Job titles most frequently captured in all three timeframes are reported in Table I.

In all three time-periods most employment opportunities were available in the academic library sector (49.6 per cent in 1999, 40 per cent in 2001/2002 and 47 per cent in 2005), followed by the public library sector (23 per cent in 1999 and in 2001/2002, and 11 per cent in 2005).

A slight problem emerges when calculating average starting salaries over the time period as a currency change occurred on January 1 2002. To create continuity in the interest of comparison, average salaries for each time period were converted to the euro rate. An average for 1999 is not available, but the overall average salary (based on single and starting point salaries) in 2001 to 2002 was €27,063.24. In 2005 the average starting and single-point salary was $€ 31,523$, representing a rise of $€ 44,59.96$ (around 16 per cent). Throughout all the time-periods surveyed most employment was available in the Eastern province of Leinster, particularly in the Greater Dublin area. This is important because the Irish rate of inflation has increased rapidly over this time period in general, and Dublin salaries need to be higher than others due to the increasingly high cost of living in Ireland's capital city. The 16 per cent rise in the average starting and single point salary between 2002 and 2005 is also reflective of the Ireland's

\begin{tabular}{lcrrrrr}
\hline & \multicolumn{2}{c}{1999} & \multicolumn{2}{c}{$2001 / 2002$} & \multicolumn{2}{c}{2005} \\
Position & Frequency & $\%$ & Frequency & $\%$ & Frequency & $\%$ \\
\hline Library assistant (all grades) & 37 & 30 & 47 & 31 & 29 & 28 \\
Assistant librarian & 23 & 19 & 34 & 23 & 30 & 29 \\
Librarian (all grades) & 28 & 23 & 34 & 23 & 17 & 17 \\
Information manager/officer etc. & 12 & 10 & 2 & 1 & 5 & 5 \\
Chief librarian posts & 9 & 7 & 6 & 4 & 2 & 2 \\
Other posts & 14 & 11 & 28 & 19 & 19 & 19 \\
\hline
\end{tabular}

Chief librarian posts

Other posts
Table I.

Frequency of job positions 
consistently high rate of inflation, which has been consistently outstripping the EU average.

Terms of employment for all three time-periods are based on advertisements where the contract details were explicitly stated. Permanent full-time and part-time positions accounted for 61.5 per cent of positions in 1999, 54.2 per cent of positions in 2001 and 2002 , but in 2005 , advertisements which explicitly stated that the positions were of a permanent nature accounted for 30.6 per cent of positions. Rather than stating this rate of change as an indicator of a fundamental change in nature of library employment in Ireland, the authors recommend caution around this figure, and instead draw attention to the fact that this type of indexing has a strong utility in refining future research questions.

Levels of experience required for applicants remained fairly consistent throughout the series. Relevant experience was essential or advantageous for 64 per cent of LIS job applicants in 1999, 69.5 per cent in 2001/2002 and 43 per cent in 2005. Holding a recognised professional LIS qualification is still desirable and essential for work in the Irish LIS sector, particularly at professional levels in the academic and public library sector. Overall, 47 per cent of jobs required a Dip.LIS or equivalent in 1999, 58 per cent in 2001/2002 and 28 per cent in 2005. The latter figure must not be taken as a reading of the decline in the need for a formal LIS qualification as a number of advertisements mentioned that candidates need to be suitably qualified.

Perhaps one of the most interesting areas where an index like this can provide clear indications of the changing nature of work in the library and information profession exists with regard to the types of skills and competencies required. The ability to use and exploit information technology is a given in our profession, but the types of abilities needed change all the time. But when compared with the more human aspects of LIS work they appear to be something of a "given". When the 1999 data is compared with the 2005 it is interesting to note that the need for solid management skills increased from just under 6 per cent to 10 per cent. More interestingly, in 1999 the skills most sought by recruiters were communication and interpersonal skills (8 per cent), but in 2005 this had increased to nearly 14 per cent.

\section{Discussion}

What emerges, even from this brief overview of the data collected during three distinct timeframes, (all of which cover a significant period of economic and social change in the Irish context) is that, although there has been some evidence of labour market constriction for library and information service workers and professionals more recently, there are still numerous opportunities available, and pay has increased. Recruitment opportunities remain most consistent for library assistant, senior library assistant, assistant librarian and librarian grades. More interestingly, although specific library and information skills and qualifications are important there is strong evidence of a presenting need for a greater range of management skills and particularly for communication and interpersonal skills amongst individuals applying for jobs.

By constructing this index, it is argued that it could be of most value to recruitment departments and recruiting managers if it was conducted in an ongoing way (i.e. as the advertisements appear), and reported on an annual basis. This would allow for a closer reading of the economic, legal and social forces, which affect the recruitment market throughout the course of the year. Changes in specific skills sought should also provide

\section{Indexing change in LIS work}

603 
LM

27,9

604 up-to-date and useful information to those involved in planning for, and providing education and training for all LIS sectors. If such an up-to-date index was prepared it would also provide opportunities for more in-depth, detailed reportage of emerging skills needs. For example, the growing need for communications and interpersonal skills is reported above. If we look specifically at the 2005 data we can get a clearer picture of exactly what this means (it transpires that employers seem to be seeking employees who are professional and pleasant with their dealings in members of the public). From a more quantitative approach, deeper focused analysis of the data can provide interesting insights into the sectoral attraction of each field. For example, in 2005, the average starting salary for an Assistant Librarian in the academic sector was $€ 32,041.21$, but in the public library sector only one salary scale is reported and it began at €35,885.

If this indexing project was to continue a few issues remain. The project is useful in indicating requirements to individuals considering a career in librarianship, but it should have a value to all concerned with the management of staff. All managers are concerned with having the best staff to represent their service and this is particularly important in the client-facing LIS sector. The wage aspect of the index will be useful to managers to make comparisons with wage expectations in other sectors, and indeed in other parts of the organisation. If the index was extended, even on a test basis, to an international level, it could provide ample opportunities for understanding the forces that drive change on a global scale in library work.

Indices such as these are always well received by the media. Journalists and editors tend to respond well to reports that are based on solid empirical data and can be easily summarised and explained. Providing data to the general and specialist media in this format could have the additional benefit of effectively "selling" librarianship as a career to individuals and further enhancing the quality of the recruitment pool. From a managerial perspective, although library administrators and managers are concerned with important issues such as resourcing, strategy and quality, recruitment indexing has an enormous potential to assist in the understanding of how change impacts on people, who are the key determinants of our professional culture. By understanding how the LIS sector changes its expectations of individuals entering the profession, we can obtain a clearer picture of how they might best be deployed in the increasingly uncertain workplace of the future.

\section{References}

Cooper, C.L. (1998), "The changing nature of work", Community, Family and Work, Vol. 1 No. 3, pp. 313-7.

Cote, C. (1989), "The library job market as from Quebec", Canadian Library Journal, Vol. 46 No. 3, pp. 165-7.

Cullen, J. (2000), "A review of library and information service job advertisements: what do they tell us about work in the Irish library sector?", Journal of Information Science, Vol. 24 No. 4, pp. 278-81.

Cullen, J. (2002), "The employment market for library and information management workers in Ireland", Library and Information Research News, Vol. 26 No. 83, pp. 17-26.

Cullen, J. (2004a), "LIS labour market research: implications for management development", Library Management, Vol. 25 No. 3, pp. 138-45. 
Cullen, J. (2004b), "Labour market research on library and information work in the Irish voluntary and community sector", Assignation, Vol. 21 No. 2, pp. 2-7.

Ehrenreich, B. (2006), Bait and Switch: The Futile Pursuit of the Corporate Dream, Granta, London.

Michaels, E., Handfield-Jones, H. and Axelrod, B. (2001), The War for Talent, Harvard Business School Press, Boston, MA.

Moore, N. (1987), The Emerging Markets for Librarians and Information Workers: LIR Report 56, The British Library, London.

Moore, N. (1988), Information-Intensive Management: It's Impact on the Employment Market for Information Professionals, Aslib, London.

Willard, P. and Mychalyn, J. (1998), "New information management work in a changing world: an Australian survey", International Journal of Information Management, Vol. 18 No. 5, pp. 315-27.

\section{About the authors}

John Cullen lectures in knowledge management and communications in the Department of Management and Allison Kavanagh is an Assistant Librarian, both at the Dublin Institute of Technology, Dublin, Ireland. John Cullen is the corresponding author and can be contacted at: john.cullen@dit.ie

\section{Indexing change in LIS work}

605

To purchase reprints of this article please e-mail: reprints@emeraldinsight.com Or visit our web site for further details: www.emeraldinsight.com/reprints 